\title{
A COMPARISON BETWEEN EVALUATION OF COMPUTER BASED TESTING AND PAPER BASED TESTING FOR SUBJECTS IN COMPUTER Programming
}

\author{
Samantha Mathara Arachchi ${ }^{1}$, Kapila Dias ${ }^{2}$, R.S. Madanayake ${ }^{3}$ \\ 1,2,3 Department of Communication and Media Technology \\ University of Colombo School of Computing, \\ 35, Reid Avenue, Colombo 7, Sri Lanka. \\ Eddy Siong Choy Chong ${ }^{4}$, \\ ${ }^{4}$ Management and Science University, Malaysia. \\ Kennedy D. Gunawardana ${ }^{5}$ \\ ${ }^{5}$ Department of Accounting, University of Sri Jayawardhanapura, Sri Lanka
}

\begin{abstract}
Evaluation criteria for different disciplines vary from subject to subject such as Computer science, Medicine, Management, Commerce, Art, Humanities and so on. Various evaluation criteria are being used to measure the retention of the students' knowledge. Some of them are in-class assignments, take home assignments, group projects, individual projects and final examinations. When conducting lectures in higher education institutes there can be more than one method to evaluate students to measure their retention of knowledge. During the short period of the semester system we should be able to evaluate students in several ways. There are practical issues when applying multiple evaluation criteria. Time management, number of students per subject, how many lectures delivered per semester and the length of the syllabus are the main issues.

The focus of this paper however, is on identification, finding advantages and proposing an evaluation criterion for Computer based testing for programming subjects in higher education institutes in Sri Lanka. Especially when evaluating hand written answers students were found to have done so many mistakes such as programming mistakes. Therefore they lose considerable marks. Our method increases the efficiency and the productivity of the student's and also reduces the error rate considerably. It also has many benefits for the lecturer. With the low number of academic members it is hard to spend more time to evaluate them closely. A better evaluation criterion is very important for the students in this discipline because they should stand on their own feet to survive in the industry.
\end{abstract}

\section{KEYWORDS}

Computer based testing, Paper based testing, Hypotheses testing

\section{Introduction}

This research was conducted by using the 2 nd year students who follow computer subjects. The main purpose of this research is to enhance the students' performance to score more marks with less programming mistakes such as syntax, punctuations errors and also to reduce the staff stress

DOI : 10.5121/ijsea.2014.5105 
International Journal of Software Engineering \& Applications (IJSEA), Vol.5, No.1, January 2014

due to paper marking [12] and save time, since there are more than five hundred answer scripts to be marked for some subjects. When marking papers in bulk (such as more than five hundred) the man-power is not enough to mark all these within the given period. Often deadlines have to be extended. Therefore marking is a terrible burden [3].

Computer based testing is a very convenient method. In addition to this, it increases the transparency of marking and students get the freedom to develop the application using their own concepts and methods. It develops their creativity as well as thinking power. Another reason is that reading coding is very hard because most of their hand writing is not so neat. Since there is no way to debug their coding there are so many errors and mistakes. This research has encountered advantages for the students as well as for the lecturers, in conducting computer based assignments in subject in computer programming [7],[9].

Students have another advantage in using machines as they do not need to remember unnecessary theories or memorise some points [4]. As we know when we are in front of the computer we will remember what to do next automatically compared with when answering a paper using a computer.

Computer training is necessary for the software developers as an on the job training. In-house staff development centers also conduct paper based examinations to measure their performance and understand about the latest concepts and technology or new programming languages [16]. Even though they are getting on the job training as well as they are in touch with the programming. According to survey questionnaire they also preferred practical based testing then the paper passed testing [17].

\section{Methodology}

\subsection{Research Methodology}

To test the proposed research model we used a survey method and collected data for analysis. The approaches followed for conducting the research include Chi Square, Analysis and Frequency Analysis.

Initially two groups have been formed as group "A" and Group "B" including 50 students for each group and the same computer programs were given to them to develop. Computers were not allocated for group " $\mathrm{A}$ " and were assigned to write on paper. Group A is the paper based testing group. The Group "B" has been provided computers to develop the same programs within the same time. Group B is the computer based testing group. Group "A" papers were evaluated by 20 lecturers and the same paper was given for Group B evaluated by the same 20 lecturers. Before filling the questionnaire which was given to the lecturers. The results were evaluated to identify the advantages of the evaluation criteria. The same tasks have been given to students who are in the group "B" to develop. Lecturers have checked only its output. But there were students who could not develop and get the final output. Only at that time the computer was used to examine the source code to assign marks [20].

After the test a questionnaire was given to both groups to identify and measure the advantages of the method. The results have been evaluated to get the feedback from them. Another questionnaire was given to the lecturers who have marked paper based testing and computer based testing to collect their views and feedback. 
International Journal of Software Engineering \& Applications (IJSEA), Vol.5, No.1, January 2014

A special questionnaire has been given to the software developers who are in the industry whose the main job is computer programming to develop software and Enterprise Resource Planning (ERP) applications. The objective of this is to measure the willingness or the views of computer based testing from the people who need to follow in-house on the job training for knowledge improvement and increments [17].

\subsubsection{The Sample}

Data was collected from 50 students of the 2nd year who followed computer subjects and 20 lecturers who teach computer subjects for higher education institutes as configuration teams. Twenty five students were females with an average age of 21 years and the other Twenty five students were males with an average age of 21 years.

The second sample was based on the 50 system developers who are really engaging with writing programming to develop software applications.

\subsubsection{Evaluate students' paper based testing}

The paper based testing answer scripts were evaluated according to the properly designed marking scheme. After marking the answers it should work perfectly without any mistakes. A Model answer script is shown below;

\begin{tabular}{|c|c|c|c|}
\hline Model Answer & \multicolumn{2}{|c|}{ Point for } & Marks \\
\hline \multicolumn{4}{|l|}{$<$ ?php. } \\
\hline Slinkz=mysql_cennect("localhost","root","12") or die ("Sorry "); & st. & () & $1 / 2 \times 6$ \\
\hline 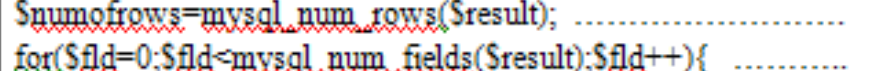 & & oop & 1 \\
\hline 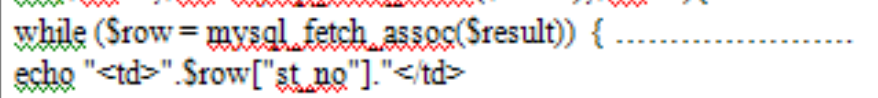 & & le loop & 1 \\
\hline 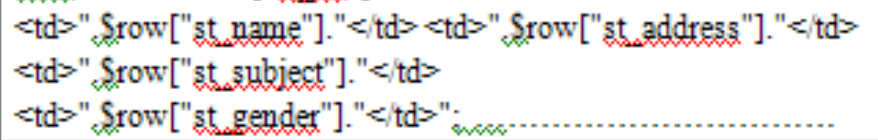 & [] & s & $1 / 2 \times 3$ \\
\hline
\end{tabular}

Figure 1. Model Answer Script 1

The answer scripts of students' who were in the group "A" (paper based testing) were evaluated and generated the following statistics. When evaluating answer scripts the marks were allocated for the key main factors of syntax, punctuations, methodology and also for the final output [20],[22]. The statistics of number of students who received marks and did not score full marks for the paper based testing as shown in the Table 1. 
International Journal of Software Engineering \& Applications (IJSEA), Vol.5, No.1, January 2014

Table 1. Number of students who received and did not score full marks from paper based testing

\begin{tabular}{|l|l|c|c|}
\hline No & Types of Mistakes & $\begin{array}{l}\text { Number of students } \\
\text { who received marks }\end{array}$ & $\begin{array}{l}\text { Number of students who } \\
\text { did not score full marks }\end{array}$ \\
\hline 1 & Semi Colon & 18 & 32 \\
\hline 2 & Colon & 10 & 40 \\
\hline 3 & Period & 12 & 38 \\
\hline 4 & Single Quotation & 15 & 35 \\
\hline 5 & Double Quotation & 16 & 34 \\
\hline 6 & Comma & 14 & 28 \\
\hline 7 & Simple Brackets & 22 & 33 \\
\hline 8 & Square Brackets & 17 & 15 \\
\hline 9 & Methodology & 35 & 41 \\
\hline 10 & Final out put & 9 & \\
\hline
\end{tabular}

Only nine students have done the coding excellently and obtained the final output with full marks. The percentage of getting full mark is $18 \%$ while $82 \%$ were there who could not score full marks due to the above reasons. The statistics of the number of students who repeatedly did mistakes for paper based testing is shown in the Table 2 .

Table 2. Number of students who repeatedly did mistakes for paper based testing

\begin{tabular}{|c|l|c|}
\hline & Number of Types of Mistakes & $\begin{array}{c}\text { Number of } \\
\text { Students }\end{array}$ \\
\hline 1 & One Mistakes & 8 \\
\hline 2 & Two Mistake s & 12 \\
\hline 3 & Three Mistakes & 7 \\
\hline 4 & Four Mistakes & 9 \\
\hline 5 & More than Four Mistakes & 5 \\
\hline
\end{tabular}

According to the above table it shows that more than $60 \%$ of students have done more than two mistakes and it is more than the average.

Screenshots of the students answer sheets are shown below. The mistakes that they have done were encircled and categorized according to one, two, three, four and more than four mistakes.

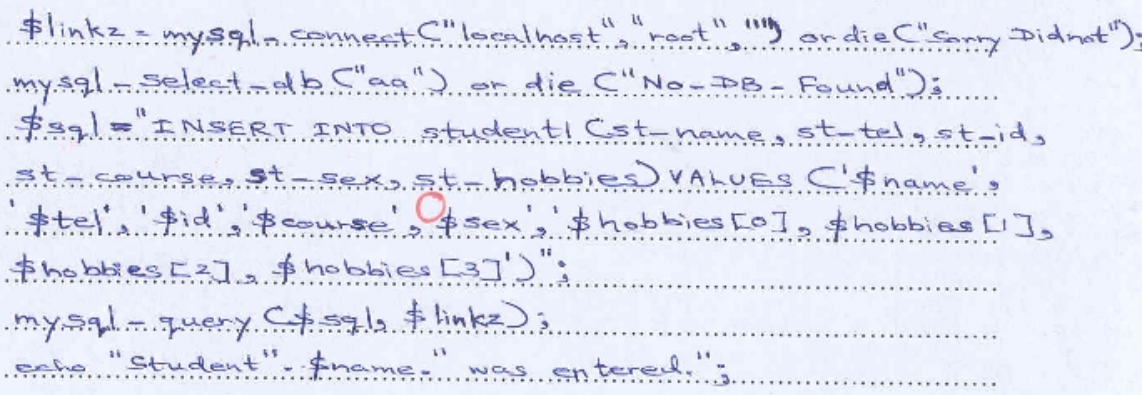

Figure 2. Student's Answer Script with one mistake 
International Journal of Software Engineering \& Applications (IJSEA), Vol.5, No.1, January 2014

The above figure (Figure 2) shows one student's paper based answer script and it has one mistake. He has missed the single quotation where the examiner has encircled. When writing a program on a piece of paper it never catches the eye or there is no way to debug the program. If you used the same coding in the machine even if the mistake is just missing a single quotation the program does not work and it takes time to find the error. Through programming experience people can catch this error. But when developing a system these tiny errors make big mistakes and take a long period recover or solve the problems.

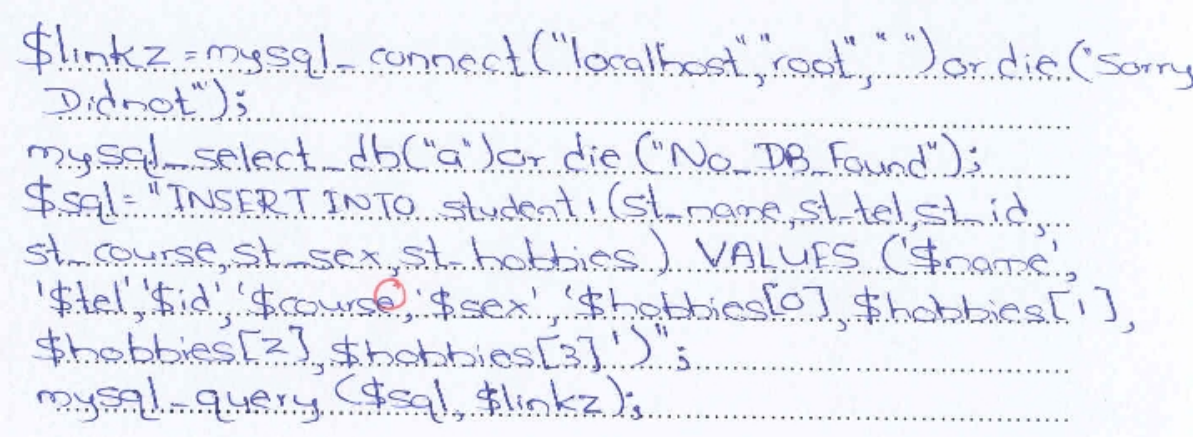

Figure 3. Student's Answer Script with one mistake

Figure three (Figure 3) also shows a single mistake. When marking answer scripts it does not catch the eye as discussed earlier. Because of that error the program also does not work. Then how can the examiner give full marks to the student because this piece of coding also does not give the output we expect.

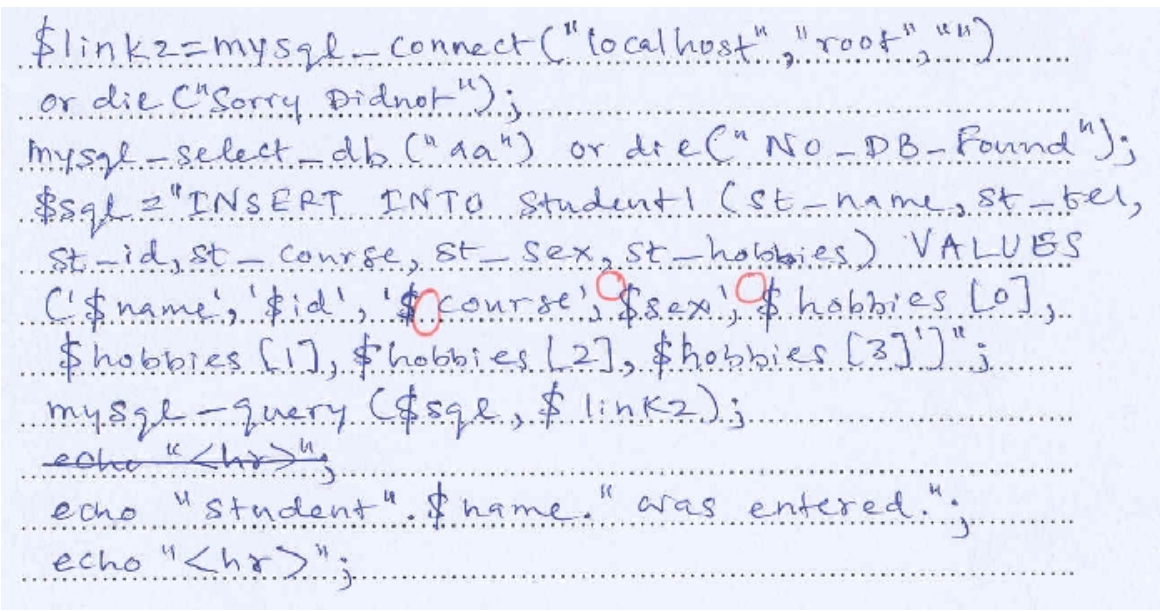

Figure 4. Student's Answer Script with three mistakes

The above figure four (Figure 4) has three mistakes. An examiner has to read all the lines with tiny symbols or needs to follow the programme syntax to check whether the piece of coding is working or not. It is a big issue to read a lot of coding as well as many lines for the programming based subjects. All these coding needs to be read line by line to catch mistakes considering 
International Journal of Software Engineering \& Applications (IJSEA), Vol.5, No.1, January 2014

possible error types such as syntax, semantic, logical and reserved key words in the mind of the examiner. Without hundred percent knowing what the student wanted to write, how can the examiner allocate full marks for the students?

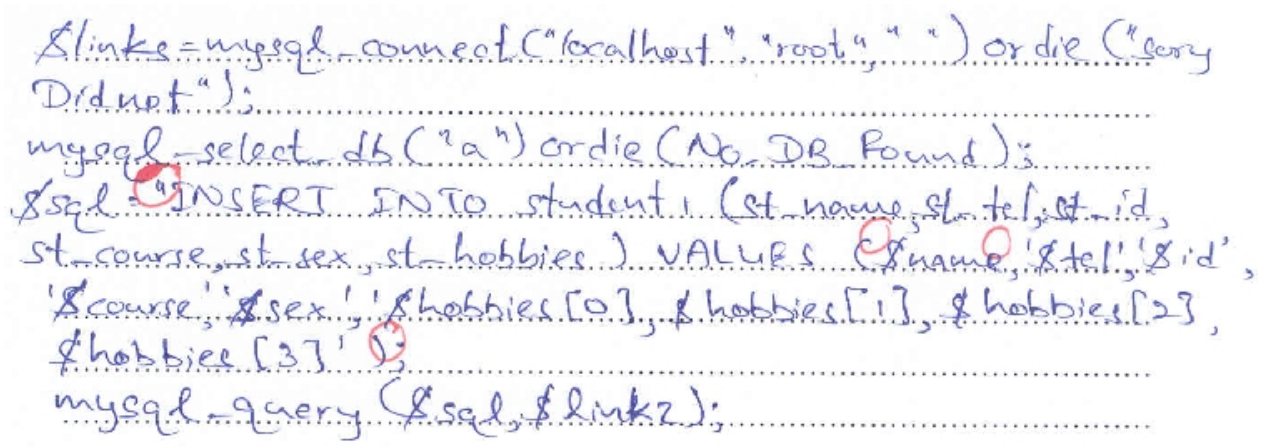

Figure 5. Student's Answer Script with four mistakes

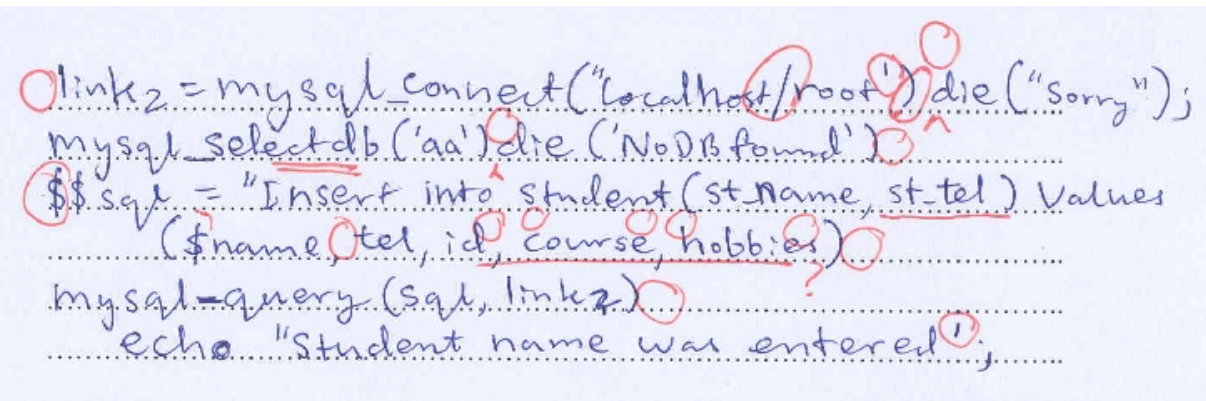

Figure 6. Student's Answer Script with more than four mistakes

The above figure (Figure. 6) has many mistakes where the examiner has encircled and underlined. When preparing and allocating marks for the above type paper it is hard because the examiner needs to have a predefine marking scheme showing how to deduct or allocate marks for the correct and incorrect points. All the marks should be able to justify.

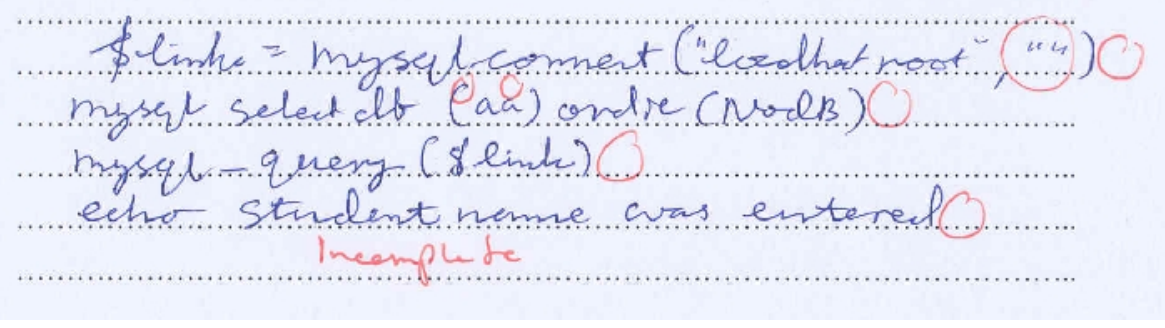

Figure 7. Student's Answer Script with more than four mistakes and incomplete lines 
International Journal of Software Engineering \& Applications (IJSEA), Vol.5, No.1, January 2014

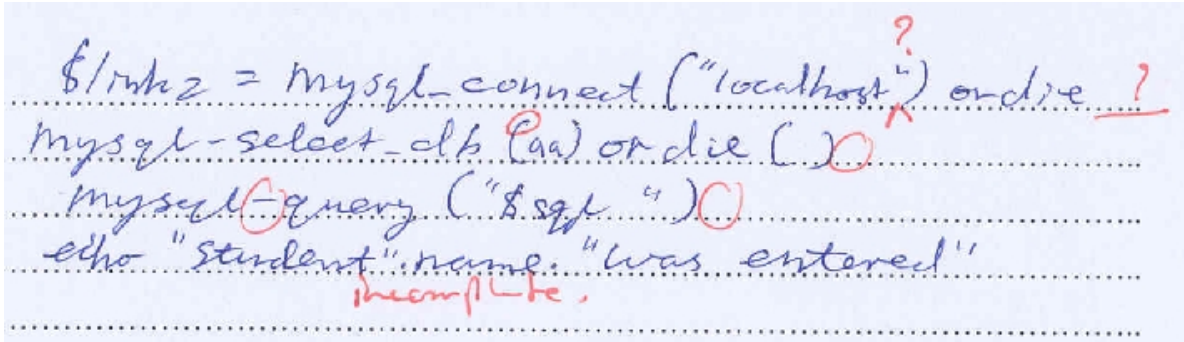

Figure 8. Student's Answer Script with more than four mistakes and incomplete lines

The above figures (Figure 7 and Figure 8) have many mistakes. Also the student has missed some important lines. Therefore the examiner should be able to completely understand and check the entire coding. Sometimes we cannot reject the student's answers saying it is not in the marking scheme, because that answer is also correct and the examiner never thought about that point of view to solve the problem.

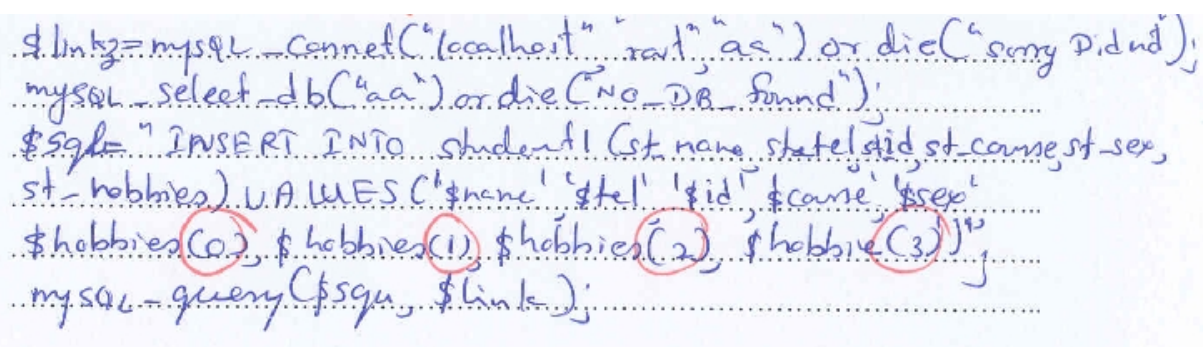

Figure 9.1. Student's Answer Script with simple brackets and square brackets mistakes

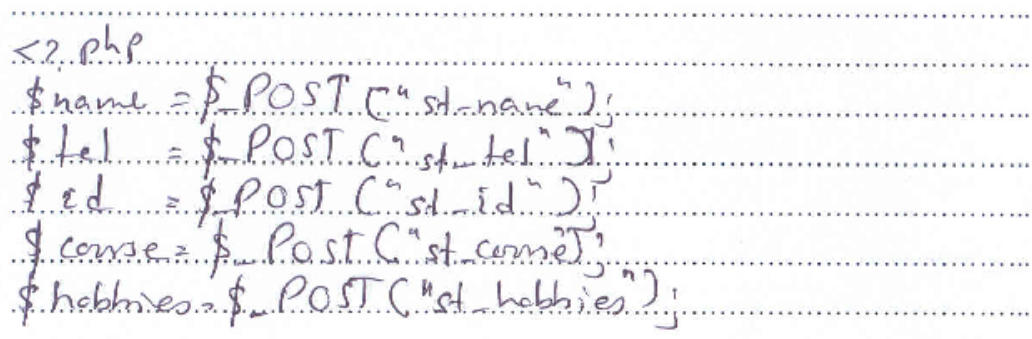

Figure 9.2. Student's Answer Script with simple brackets and square brackets mistakes

The students have been done mistakes in selecting the correct types of brackets. For instance some of the students have used simple brackets instated of square brackets. Either it could be carelessness or they really do not know about the correct type of brackets as shown in the figure 9.1 and 9.2 (Figure 9.1 and 9.2). 
International Journal of Software Engineering \& Applications (IJSEA), Vol.5, No.1, January 2014

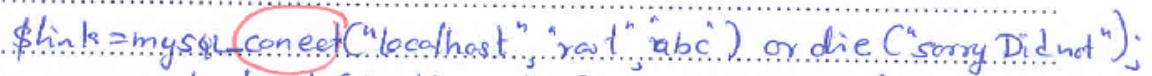

$$
\begin{aligned}
& \text { mysqr select db( "aa".) or die ("No DB Found")' }
\end{aligned}
$$

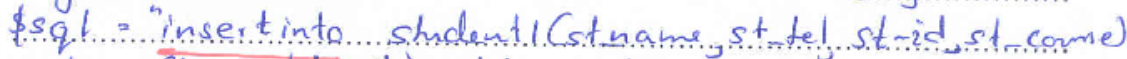

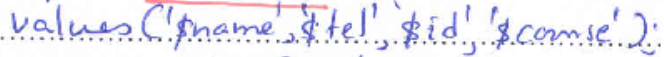

$$
\begin{aligned}
& \text { mysg.t. quary (\$sql } \$ \text { lint.2)! }
\end{aligned}
$$

Figure 10. Student's Answer Script with spelling mistakes

Some of the students used wrong spelling for reserved keywords in that particular language such as "mysql_connect". In here students have spelled it as "mysql_conect" as shown in the above figure 10 (Figure 10). This coding is also not working correctly to get the expected output. Most of the programming tools do not have spelling checkers. The Examiner as well as the programmer needs to be careful about spelling and self confident in order to reduce the mistakes and save time.

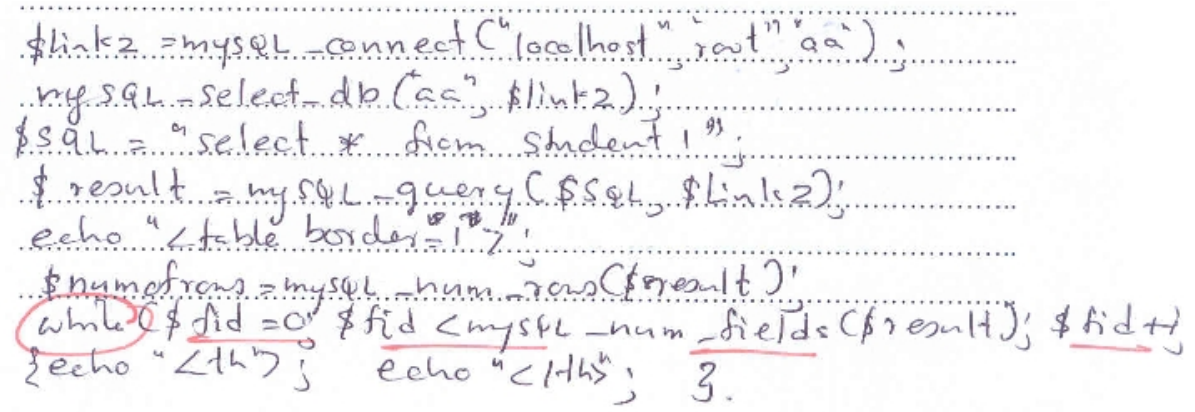

Figure 11. Student's Answer Script with mistakes in the methodology

Some answer scripts were found with wrong programming methodology or wrong structure. Figure 11 (Figure 11) has such a mistake instead of the "for loop", the while loop has been used.

\subsubsection{Evaluation of the students' questionnaire}

After doing the above paper based testing students who were in the group "A" filled a questionnaire to express their own attitudes towards this type of paper based testing. The statistics are shown in the Table 3. 
International Journal of Software Engineering \& Applications (IJSEA), Vol.5, No.1, January 2014

Table 3. Number of students who answered questionnaires for paper based testing

\begin{tabular}{|l|l|c|c|}
\hline \multirow{2}{*}{ No } & \multirow{2}{*}{ Reason } & \multicolumn{2}{|l|}{ Number of Students } \\
\cline { 3 - 4 } & & Yes & No \\
\hline 1 & Need to memorise concepts and unnecessary theory & 40 & 10 \\
\hline 2 & Reduce stress & 15 & 35 \\
\hline 3 & More confident about answers & 17 & 23 \\
\hline 4 & Answer is visible & 0 & 50 \\
\hline 5 & Working in front of machine is comfortable & 50 & 0 \\
\hline 6 & Interface provides the extra support & 45 & 5 \\
\hline 7 & Can debug time to time to make it correct & 0 & 50 \\
\hline 8 & More freedom to come up with alternative methods & 0 & 50 \\
\hline 9 & Easy to score maximum marks & 8 & 42 \\
\hline
\end{tabular}

\subsubsection{Evaluation of students - computer based testing}

Students who were in the group "B" were allocated for the computer based testing [5], [23] and the results given in table 4 have been obtained. When evaluating these outputs initially the examiner has checked whether the students have received the correct outputs or not and the coding was evaluated only for the students who couldn't complete it within the given time [24]. The statistics of the number of students who did not score full marks from computer based testing is shown in the Table 4.

Table 4. Summary of Number of students who received and who did not score full marks from computer based testing

\begin{tabular}{|l|l|c|c|}
\hline No & Types of Mistakes & $\begin{array}{c}\text { Number of students who } \\
\text { received marks }\end{array}$ & $\begin{array}{c}\text { Number of students who } \\
\text { did not score full marks }\end{array}$ \\
\hline 1 & Semi Colon & 42 & 8 \\
\hline 2 & Colon & 45 & 5 \\
\hline 3 & Period & 43 & 7 \\
\hline 4 & Single Quotation & 42 & 8 \\
\hline 5 & Double Quotation & 47 & 3 \\
\hline 6 & Comma & 46 & 2 \\
\hline 7 & Simple Brackets & 48 & 11 \\
\hline 8 & Square Brackets & 39 & 9 \\
\hline 9 & Methodology & 41 & 12 \\
\hline 10 & Final out put & 38 & \\
\hline
\end{tabular}

According to the above statistics only thirty eight students have done the coding excellently with the final output and obtained full marks. The percentage of those getting full marks is $76 \%$.

The number of students who have repeatedly done mistakes was also less due to facilities for debugging while they were developing programmes. The system itself has shown to them the syntax errors. There were students who could not complete the programme during the allocated time but their performance is better than for paper based testing. The statistics of the number of students who repeatedly did mistakes for computer based testing is shown in the Table 5. 
International Journal of Software Engineering \& Applications (IJSEA), Vol.5, No.1, January 2014

Table 5. Number of students who repeatedly did mistakes for computer based testing

\begin{tabular}{|l|l|l|}
\hline & Number of Types of Mistakes & Number of Students \\
\hline 1 & One Mistake Type & 6 \\
\hline 2 & Two Mistake Types & 3 \\
\hline 3 & Three Mistake Types & 1 \\
\hline 4 & Four Mistake Types & 2 \\
\hline 5 & More than Four Mistake Types & 0 \\
\hline
\end{tabular}

After doing the above computer based testing [6] the students who were in the group " $\mathrm{B}$ " filled a questionnaire to express their own attitudes towards this type of computer based testing. The statistics are shown in Table 6.

Table 6. An Analysis of feedback given by students who answered the questionnaire for computer based testing

\begin{tabular}{|l|l|l|l|}
\hline No & Reason & \multicolumn{2}{l|}{ Number of Students } \\
\cline { 3 - 4 } & & Yes & No \\
\hline 1 & Need to memorise the concepts and unnecessary theory & 10 & 40 \\
\hline 2 & Reduce stress & 42 & 8 \\
\hline 3 & More confident about answers & 35 & 15 \\
\hline 4 & Answer is visible & 50 & 0 \\
\hline 5 & Working in front of machine is comfortable & 50 & 0 \\
\hline 6 & Interface provides the extra support & 45 & 0 \\
\hline 7 & Can debug time to time to make it correct & 50 & 0 \\
\hline 8 & More freedom to come up with alternative methods & 50 & 0 \\
\hline 9 & Easy to score maximum marks & 46 & 4 \\
\hline
\end{tabular}

\subsubsection{Feedback from the lecturer's who evaluated paper based testing and computer based testing}

The twenty lecturers who evaluated paper based examinations have given their feedback according to the questionnaire. The statistics are shown in the Table 7. 
International Journal of Software Engineering \& Applications (IJSEA), Vol.5, No.1, January 2014

Table 7. An Analysis of feedback given by lecturers who answered the questionnaire for computer based testing

\begin{tabular}{|l|l|l|l|}
\hline No & \multicolumn{1}{|l|}{ Reason } & \multicolumn{2}{l|}{$\begin{array}{l}\text { Number of } \\
\text { Lecturer }\end{array}$} \\
\cline { 3 - 4 } & & \multicolumn{2}{l|}{ Yes } \\
\hline 1 & Reduce the stress, over head and ambiguity & 20 & 0 \\
\hline 2 & Reduce Paper marking time & 15 & 5 \\
\hline 3 & Increase the accuracy of marking & 20 & 0 \\
\hline 4 & More effective and efficient & 20 & 0 \\
\hline 5 & No need to read line by line to check syntax for mistakes & 20 & 0 \\
\hline 6 & Reduce the unpleasant situation of reading untidy handwriting & 20 & 0 \\
\hline 7 & Increase the transparency of marking & 20 & 0 \\
\hline 8 & $\begin{array}{l}\text { 100\% certainty about the correctness of the coding and It gives working } \\
\text { outputs }\end{array}$ & 20 & 0 \\
\hline 9 & $\begin{array}{l}\text { Ability to use different techniques or methods by their own need not } \\
\text { stick to one method }\end{array}$ & 20 & 0 \\
\hline 10 & Debugging method can be used to evaluate the incomplete programmes. & 18 & 2 \\
\hline
\end{tabular}

\subsubsection{Feedback from Software Developers}

The selected fifty software developers went through the training and really faced the pre-test and post test as a requirement of on the job training to move to the new project which is totally based on different languages or to obtain the next increment level [19],[21]. The statistics are given in the table 8 .

Table 8 . Feedback from the software developers in the Industry

\begin{tabular}{|l|l|l|}
\hline Type of test & $\begin{array}{l}\text { No of } \\
\text { Employees }\end{array}$ & $\begin{array}{l}\text { No of } \\
\text { Employees (\%) }\end{array}$ \\
\hline $\begin{array}{l}\text { No of employees who preferred computer based testing to } \\
\text { evaluate themself after the training session }\end{array}$ & 43 & 76 \\
\hline $\begin{array}{l}\text { No of employees who does not prefer computer based } \\
\text { testing to evaluate themself after the training session }\end{array}$ & 07 & 14 \\
\hline $\begin{array}{l}\text { No of employees who does not response for the } \\
\text { Questionnaire }\end{array}$ & 05 & 10 \\
\hline
\end{tabular}

Software developers and the IT industry used this practical based method especially for the junior employees or those undergoing training programmes to enhance their knowledge. With the practical knowledge and the experience they can face this type of evaluation criteria more confidently [24]. 
International Journal of Software Engineering \& Applications (IJSEA), Vol.5, No.1, January 2014

\section{Hypotheses testing}

\subsection{Comparison between Paper based Testing and Computer based Testing (Using two sample proportion tests)}

Table 8. Result of two sample proportion tests

\begin{tabular}{|l|l|l|l|}
\hline & Received Marks & Lost Marks & Total \\
\hline Paper based Testing & 168 & 332 & 500 \\
\hline Computer based Testing & 431 & 69 & 500 \\
\hline Total & 599 & 401 & 1000 \\
\hline
\end{tabular}

$$
\hat{p}_{1}-168 / 500, \quad \hat{p}_{2}-431 / 500
$$

Therefore we can conclude that; the true proportion of students who received marks from computer based testing is higher than the true proportion of students who received marks from paper based testing.

Ho: The true proportion of students who received marks from paper based testing and Computer base testing is the same

H1: The true proportion of students who received marks from computer based testing is higher than the true proportion of students who received marks from paper based testing.

Test statistic:

$$
\begin{aligned}
& Z=\frac{\hat{p}_{1}-\hat{p_{2}}}{\sqrt{\frac{\hat{p}_{1}\left(1-\hat{\left.p_{1}\right)}\right.}{n_{1}}+\frac{\hat{p}_{\mathbf{z}}\left(1-\hat{\left.p_{2}\right)}\right.}{n_{2}}}}=-20.11 \sim N(0,1) \\
& \text { p value }=\operatorname{Pr}(Z \leq-20.11)=3.01 * 10^{-90}
\end{aligned}
$$

Since the $\mathrm{p}$ value $\left(3.01 * 10^{-90}\right)$ is extremely small we have enough evidence to reject Ho at any level of significance.

\subsection{Comparison between the Computer based and Paper based questions among students (Using two sample proportion test)}

Table 9. Comparison between the Computer based and Paper based questionnaires

\begin{tabular}{|l|l|l|l|}
\hline Type of test & Yes & No & Total \\
\hline Paper based testing & 175 & 265 & 440 \\
\hline Computer based testing & 378 & 67 & 445 \\
\hline
\end{tabular}

$$
\hat{p}_{1}=175 / 440, \quad \hat{p}_{2}=378 / 445
$$


International Journal of Software Engineering \& Applications (IJSEA), Vol.5, No.1, January 2014

Ho: The true proportions of students who prefer computer based questions are the same as the true proportions of students who prefer paper based questions

H1: The true proportions of students who prefer computer based questions are higher than the true proportions of students who prefer paper based questions

Test statistic:

$$
\begin{aligned}
& Z=\frac{\hat{p}_{1}-\hat{p}_{2}}{\sqrt{\frac{\hat{p}_{1}\left(1-\hat{p}_{1}\right)}{n_{1}}+\frac{\hat{p}_{2}\left(1-\hat{p}_{2}\right)}{n_{2}}}}=-15.66 \sim N(0,1) \\
& \text { pvalue }=\operatorname{Pr}(Z \leq-15.66)=1.42 * 10^{-55}
\end{aligned}
$$

Since the $p$ value $\left(1.42 * \mathbb{R} 10 \mathbf{\Xi}^{\boldsymbol{\top}}(-\mathbf{5 5})\right)$ is extremely small we have enough evidence to reject $H_{o}$ at any level of significance.

Therefore we can conclude that; the true proportions of students who prefer computer based questions are higher than the true proportions of students who prefer paper based questions.

\subsection{Evaluation of the questionnaire feedback from lecturers for Computer based Testing}

Let $P$ be the true proportion of lecturers who prefer computer based questions

$$
\begin{aligned}
& H_{\circ}: p=0.5 \\
& H_{1}: p>0.5 \\
& \hat{p}=193 / 200
\end{aligned}
$$

Test statistic:

$$
\begin{aligned}
& Z=\frac{\hat{p}}{\sqrt{\frac{\hat{p}(1-\hat{p})}{n}}}=74.26 \sim N(0,1) \\
& \text { pvalue }=\operatorname{Pr}(Z \geq 74.26)=0.0000
\end{aligned}
$$

Since the p value (0.0000) is extremely small we have enough evidence to reject Ho at any level of significance. Therefore we can conclude that the true proportions of lecturers who prefer computer based testing are higher than 0.5 and hence most of them prefer computer based testing.

\subsection{Evaluation of the questionnaire feedback from software developers in the industry for computer based Testing}

According to the selected software developers $76 \%$ were preferred for the computer based testing and 14\% did not prefer and 10\% did not respond. Therefore the people like software developers whose job is really writing programmes also preferred to have computer based testing than a paper for pre or post test. 


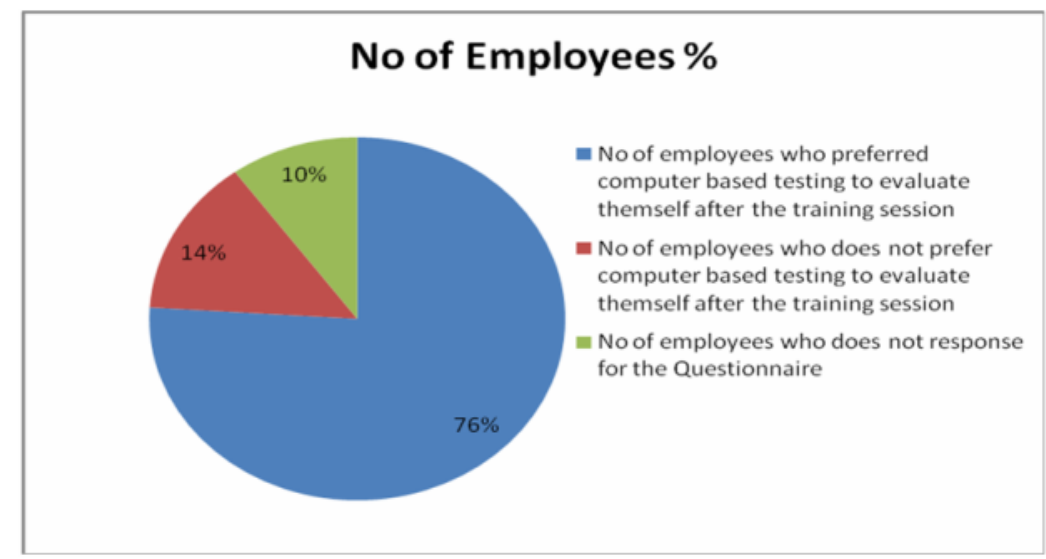

Figure 3. Feedback Pie chart from software developers

\section{Conclusion and Discussion}

This section of the study highlights the key findings and is discussed in relation to the objectives defined at the prior stages of this research. The main aim of the discussion is to bring to light new findings and value additions to the area of testing for the higher education sector especially in computer related subjects to conduct the computer based testing than the paper based testing. It would be beneficial to the students and the lecturers.

According to the students' questionnaire $85 \%$ said that computer based testing is much better and they have proved it is more successful than the paper based testing due to the following advantages;

No need to by-heart concepts and unnecessary theory, Reduce stress, Build more confidence about the answers, The answer is visible, Working in front of computer is more comfortable, Interface provides the extra support, Ability to debug time to time to make it correct, More freedom to come up with alternative methods and Easy to score maximum marks.

The data was also analysed according to the given questionnaire to summarize the results from the lecturers' point of view. Ten key important factors have been identified for conducting computer based testing;

Reduce the stress, Over-head and ambiguity, Reduce marking time, increase the accuracy of marking, It is a more efficient and effective method, Does not need to read line by line to check syntax for mistakes, Reduces the unpleasant situation of reading untidy handwriting, Increases the transparency of marking, Hundred percent of certainty about the correctness of the coding, Production of a working output, Ability to use different techniques or methods on their own, No need to stick to one method and debugging method can be used to test the logical errors in the programs.

According to the survey conducted the software developers from the industry also preferred to have a testing method for their in-house on the job training programmes. 


\section{REFERENCES}

[1] Anderson D., Black D.,Brown S., Day A., McDowel S.1, McDowell L.,Peters L.\& Smith B. 1999, p. 125.

[2] Computer-based testing: a comparison of computer-based and paper-and-pencil assessment. [Online]. Available: 12.03.2013

[3] http://www.thefreelibrary.com/Computer-based+testing\%3a+a+comparison+of+computerbased+and...-a0241861838

[4] Anderson D., Black D.,Brown S., Day A., McDowel S.1, McDowell L.,Peters L.\& Smith B. 1999, p. 170

[5] Anderson D., Black D.,Brown S., Day A., McDowel S.1, McDowell L.,Peters L.\& Smith B. 1999, p. 139).

[6] Computer Based $\quad$ Testing. $\quad$ [Online]. $\quad$ Available: $\quad 12.03 .2013$ http://www.nremt.org/nremt/about/CBT_home.asp

[7] What are important aspects of converting an exam to computer-based testing? [Online]. Available: 15.03.2013.

[8] http://www.proftesting.com/test_topics/cbt.php

[9] Roy Clariana and Partricia Wallace: Paper based versus computer based assessment: Vol 33 No. 5 2002 593-602" British Journal of Educational Technology

[10] Heather F., Steve K. \& Stephanie M. 1999, A Hand book for Teaching and Learning in Higher Education, Kogan Page Limited .p. 134

[11] Anderson D., Black D.,Brown S., Day A., McDowel S.1, McDowell L.,Peters L.\& Smith B. 1999, p. 113

[12] Badders, W 2000, Methods of Assessment, viewed 3 August 2012,

[13] <http://www.eduplace.com/science/profdev/articles/badders.html>.

[14] Habeshaw S.,Gibbs G.,Habeshaw T. 1986, p. 57, 53 Interesting ways to assess your students,

[15] Newble, Cannon R. \& David 2000, p. 202, A Hand book for Teachers in Universities and Colleges

[16] Honey P \& Mumford A 1992, The Manual of Learning Styles, 3rd edn, Maidenhead: pete Honey., Viewed 15 May 2012 www.studyskills.soton.ac.uk/studyguides/Learning\%20styles.doc>

[17] Anderson D., Black D.,Brown S.,Day A. McDowel S.I.McDowell L.,Peters L \& Smith B.1999, P.4

[18] A Hand book for Teachers in Universities and colleges (Newble, Cannon R \& David 2000, pp. 173205)

[19] Littlejohn, A 1993, 'Teaching school aged learners : a framework for understanding and some indicators for change'.

[20] R.D. Dowsing and S. Long,(1997),"The Do's and Don'ts of Computerising IT Skills Assessment",University of East Anglia, NORWICH NR4 7TJ, UK

[21] Helen Drury, (1997), "Integrating the Teaching of Writing Skills into Subject Area IT Programs", Learning Assistance Centre, The University of Sydney

[22] Michael J. Hannafin, (1997), "Educational Technology Research \& Development (1997), 45(3), 101 117., University of Georgia,Athens, GA USA 30602

[23] Mary T. Rice , (1997),"Finding out What Works: Learning from Evaluations of Information Technologies in Teaching and Learning", Deakin Centre for Academic Development, Deakin University

[24] Lynette Schaverien and Mark Cosgrove, (1997), "Computer Based Learning Environments in Teacher Education: Helping Students to think Accurately, Boldly and Critically”.

\section{Authors}

Samantha Mathara Arachchi, is a Lecturer at the Department of Communication and Media Technology (CMT), University of Colombo School of Computing (UCSC), Sri Lanka, who obtained his degree in Bachelor of Science in 1999 from the Open University of Sri Lanka. He holds a Postgraduate Diploma in Computer Technology in 2002 from the University of Colombo and a Postgraduate Diploma in Information Management in

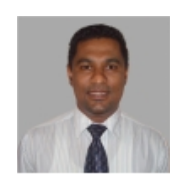
2007 from Sri Lanka Institute of Information Technology, and also holds a Masters in Information Management (2008) with merit pass. He is reading for $\mathrm{PhD}$ in Malaysia in Computer Science. 
International Journal of Software Engineering \& Applications (IJSEA), Vol.5, No.1, January 2014

Dr. Kennedy D Gunawardana is a Professor in the Accounting Depatment at University of Sri Jayawardenapura, He teaches Cost and Management Accounting, Accounting Information Systems, and Artificial Neural Networks for Accountig for the undergraduates and Post graduates students.With over 50 articles published in refereed Conferences procedings, numerous other papers and monographs, 2 chapters of the international books and 3 English Medium text books and 3 Sinhala medium edited books.

R.S. Madanayake is a Lecturer attached to the University of Colombo School of Computing, Sri Lanka. He obtained his B.Sc. from the University of Colombo, Sri Lanka in 2001. He obtained his M.Sc. in IT from the University of Colombo, Sri Lanka in 2010. He is currently reading for his M.Phil. at the University of Colombo, Sri Lanka.

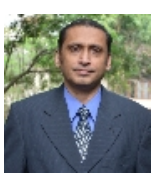

G.K.A. Dias is a Senior Lecturer at the University of Colombo School of Computing and is currently the head of its Department of Communication and Media Technologies. He obtained his B.Sc. from the University of Colombo in 1982. He obtained a Post Graduate Diploma in Computer Studies from the University of Essex, U.K. in 1986. He obtained an MPhil by research from the University of Wales, U.K. in 1995.
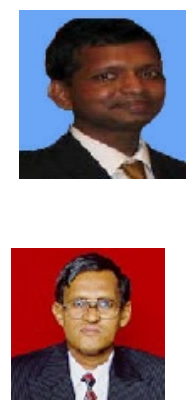